\title{
Programas Desenvolvidos na Residência Multiprofissional: Desafios Vivenciados Pela Terapia Ocupacional
}

\author{
Toldrá, Rosé Colom; Batista, Marina Picazzio Perez; Souto, Ana Cristina Fagundes; \\ Freitas, Dionne do Carmo Araújo; Etyoshioka, Eliani Tiemi; \\ Almeida, Maria Helena Morgani de
}

Universidade de São Paulo Departamento de Fisioterapia, Fonoaudiologia e Terapia Ocupacional da Faculdade de Medicina - rosetoldra@usp.br

Introdução: o Programa de Residência Multiprofissional ora descrito é desenvolvido em um hospital público universitário de média complexidade desde 2012, sendo constituído, entre outras áreas de concentração, pela área de Saúde do Adulto e do Idoso. a área de concentração ocorre em colaboração entre docentes e profissionais de fisioterapia, fonoaudiologia, terapia ocupacional e farmácia. o programa integra atividades de ensino em serviço, pesquisa e extensão. a perspectiva multiprofissional compõe os paradigmas de promoção da saúde e cuidado, tendo em vista que o alívio do sofrimento humano requer um planejamento multiprofissional, com atuação integrada de diversas áreas de atuação. Objetivo: Apresentar os programas criados a partir do trabalho multiprofissional envolvendo a Terapia Ocupacional. Métodos: Trata-se de um trabalho descritivoreflexivo acerca dos projetos desenvolvidos na residência multiprofissional pela Área de Concentração do Adulto e do Idoso dos quais a Terapia Ocupacional participa. Resultados: Os programas criados a partir da análise das demandas dos usuários abrangem a atenção hospitalar, ambulatorial e após a alta visando maior integralidade do cuidado nohospital e a partir dele. o projeto de atenção na enfermaria de clínica médica é desenvolvido às pessoas adultas e idosas que apresentam limitação na realização das atividades. o programa de apoio à alta realiza encaminhamentos para a rede de serviços da região após a saída do hospital bem como o seguimento via telefone para apoiar o acesso aos diferentes serviços de saúde e sociais. Quanto às propostas ambulatoriais destacam-se o projeto de atenção ao paciente neurológico, saúde da mulher, o programa de estimulação da memória e reabilitação vestibular, e a inserção nos grupos de prevenção de quedas já desenvolvidos. Discussão: Todos os projetos são multiprofissionais e almejam uma atuação ética, crítica e efetiva utilizando-se dos norteadores da promoção de saúde, integralidade e humanização do cuidado. Entretanto, enfrentam-se alguns desafios para a sustentação de uma atuação hospitalar orientada para a multiprofissionalidade em um ambiente pouco acostumado a tais intervenções e identificada com uma atenção centrada nos sintomas e na doença, o que compromete em muitas ocasiões a identificação, compreensão e a atenção às múltiplas necessidades sociais e de saúde da população. Também se mostra desafiadora a prestação da atenção integral em rede serviços, que ainda funcionam de forma desarticulada e muitas vezes pouco resolutiva. Conclusão: Considera-se que a atuação do terapeuta ocupacional na perspectiva da multiprofissionalidade é essencial para a sua formação, contribuindo para a melhoria da qualidade da atenção à saúde das pessoas, das famílias e grupos sociais atendidos no hospital e uma oportunidade privilegiada para o reconhecimento da contribuição desse profissional no contexto da operacionalização das políticas do Sistema Único de Saúde.

Toldrá, Rosé Colom; Batista, Marina Picazzio Perez; Souto, Ana Cristina Fagundes; Freitas, Dionne do Carmo Araújo; Etyoshioka, Eliani Tiemi; Almeida, Maria Helena Morgani de. Programas Desenvolvidos na Residência Multiprofissional: Desafios Vivenciados Pela Terapia Ocupacional. In: Anais do Congresso Internacional de Humanidades \& Humanização em Saúde [= Blucher Medical Proceedings, num.2, vol.1]. São Paulo: Editora Blucher, 2014. ISSN 2357-7282

DOI 10.5151/medpro-cihhs-10502 